\title{
Some Thoughts on the Fermi Paradox and Extensions to the Kardashev Scale in Relation to Theology
}

\author{
David O. F. Skibinski ${ }^{1}$ \\ ${ }^{1}$ Swansea University
}

June 3, 2020

\begin{abstract}
The Fermi paradox concerns the possible existence of advanced extraterrestrial civilizations. The Kardashev scale envisages advanced civilizations that may control and consume energy up to a galactic scale. Postulated extensions of the scale consider advanced entities that are powerful enough to create new universes. In an eternal existence of multiple universes, the emergence of such an entity may be inevitable. Such an advanced entity could perhaps be of sufficient greatness to be God. The scientific and theological feasibility of this idea of God is discussed. A possible advantage of viewing God in this way is that the supernatural might be dispensed with. However, from the viewpoint of religious practice, it is not clear whether such a God would be acceptable to major religions.
\end{abstract}

\section{Advanced Civilizations Elsewhere in the Universe}

The Fermi paradox is the conflict between the expectation that intelligent life may be common in the universe with there being little firm scientific evidence of extraterrestrial civilizations (for example, Webb 2015; Ćirković 2018). There is no clear support for any explanation of the paradox and thus it remains unresolved. There is however little scientific obstacle to the belief that we are not alone in the universe. This belief is also in accord with the Copernican principle, widely investigated in cosmology (for example, Clarkson et al. 2008), that there is no clear justification for assuming that humans occupy a special, unique or privileged position as observers of the universe (Rowan-Robinson 1996).

Kardashev (1964) introduced a three-point scale which describes the technological development of civilizations according to their energy consumption. Points I, II, and III correspond to energy consumptions for a planet such as Earth, its own star, and its own galaxy, respectively. Many refinements and developments of the scale have been considered including upward extensions to advanced civilizations powerful enough to control multiple universes or to create new universes (Galantai 2003; Cirkovic 2015), and to scales involving criteria other than energy (Zubrin 1999). A well-known adage is that to humans any sufficiently advanced technology is indistinguishable from magic (Clarke 1973). This was reworded or paraphrased in the suggestion that any sufficiently advanced extraterrestrial intelligence is indistinguishable from God. Perhaps this entity need not be omnipotent and omniscient, but to us it would seem to be God (Shermer 2002). This idea was extended to suggest that interstellar extraterrestrials may be God based on their descriptors (Richey 2019). The purpose of this essay is to consider such ideas further, and discuss and develop the idea that God could have emerged by natural scientific forces rather than be a supernatural being.

The very existence of humans provides evidence of the power of evolution to create adaptations and intelligent life, and there is every reason to believe that natural selection would be effective elsewhere in the universe (Levin et al. 2019). Similarly, there seems no reason to doubt that cultural and technological evolution would also be effective elsewhere in the universe. Thus, the hypothesis that natural forces could create very advanced intelligent entities as envisaged on the Kardashev scale cannot be rejected based on our current scientific knowledge. One aspect of cultural and technological evolution is the idea of the 
technological singularity which envisages a runaway process leading to a superintelligence far surpassing current human capabilities (Vinge 1993; Kurzweil 2005). In a theological context a related idea is that of Teilhard de Chardin who envisaged evolution leading humans and the universe towards a future final point of spiritual unification called the Omega Point (Grumett 2007). Although the concept of the technological singularity may be applied to events in past human evolution (da Costa 2019), its main use is prospective and concerned with the future fate of humanity and the universe. It is thus less consistent with the notion of a God who acted in the distant past to create the universe and everything as we see it now.

\section{Advanced Civilizations in Universes and Multiverses}

Many estimates have been made of the number of extraterrestrial civilizations using approaches such as the Drake equation. These estimates vary considerably according to the many assumptions made, and range from millions to zero (for example, Drake and Sobel 1992; Wilson 2001; Forgan 2009; Frank and Sullivan 2016; Sandberg et al. 2018). Considerations include whether the estimates apply to the Milky Way or the observable universe, include past and future civilizations, and whether communication constraints such as the speed of light are considered. The likelihood of the evolution of advanced Kardashev civilizations or entities should be higher if the entire universe rather than just the observable universe is included. Estimates of the size of the entire universe relative to the observable universe are also uncertain ranging from around 251 times greater (Vardanyan et al. 2011) to very many orders of magnitude greater (Guth 1997). Other things being equal, the likelihood of emergence of an advanced entity should be greater in a large than a small universe.

This reasoning can be extended to the emergence of advanced entities in a multiverse consisting of many individual universes. Multiverse theories include the idea that our universe is infinite with every possibility realised in some part of it, eternal inflation with an infinite number of pocket universes, and the many worlds interpretation of quantum mechanics (see Tegmark 2003; Page 2008). Another idea is that black holes within universes may spawn offspring universes (Smolin 1997; Smolin 2004; Vaas 2003). The multiverse is a substantial area for investigation and analysis in theology and philosophy as well as in physics. The possibility that God may or may not have created the multiverse has been discussed (Page 2008; Chan 2015), as has the relevance of the multiverse to the problem of evil (Megill 2011; Kraay 2013; Ignatova 2019; Rogers 2020 ). Multiverse ideas have also been used in discussion of the nature or existence of God involving modal realism and possible worlds (Kraay 2010) and in proofs of the existence of God (Spitzer 2019).

The likelihood of an advanced entity capable of creating and controlling new universes arising in an infinitely large multiverse (including an infinitely large universe) should be greater than in a single universe of finite size. In this context, appeal can also be made to the plenitude principle that no genuine potentiality of being can remain unfulfilled (Lovejoy 1976; Kane 1976; Kragh 2019). It could thus be inevitable that such an advanced entity will evolve somewhere at some time in an eternal existence of a potentially infinite number of universes, even if the probability of any given universe generating advanced entities is low.

\section{Emergence of God in a Multiverse}

The idea that an advanced entity or civilization from another universe created our own universe was proposed previously (for example, Harrison 1995; Gribbin 2010; Vidal 2015). Many science fiction stories also portray entities with godlike properties (see examples in Appendix 1). Some solutions of the Fermi paradox envisage that extraterrestrials are responsible for manufacturing our world as we see it. For example, the zoo hypothesis proposes that Earth is a zoo or reserve created by extraterrestrials who are secretly observing us (Ball 1973). The planetarium hypothesis proposes that we are living in a simulation created by extraterrestrials (Baxter 2000). This latter hypothesis considers that the simulation is created by a Type III Kardashev civilization possessing energy on the scale of its own galaxy. Although all these ideas may envisage a creator of our universe or world, it is not generally envisaged that this creator 
is God. The creator is depicted more as an advanced entity representing an alternative to God as a creator.

The idea considered in this essay is that an advanced entity of sufficient greatness has emerged naturally and inevitably from a potentially infinite number of universes, as in a multiverse, and that this entity is God. Emphasis is on the inevitability of this happening given the power of natural and technological evolution, the potential infinity of universes, and with appeal also to the plenitude principle. Many ontological proofs of the existence of God consider God to be a supremely or maximally great or perfect being (see for example, Oppy 2018). For example, the proof of St Anselm considers God as a being "than which nothing greater can be thought", where greatness can be in qualities such as omnipotence and omniscience. So, appealing again to the unlimited possibilities for evolution in a potentially infinite number of universes and the plenitude principle, this maximal greatness on a scale such as an extended Karadashev scale could also be inevitable.

A distinction can be drawn between the emergence of an advanced entity on a Kardashev scale capable of creating worlds or universes and a maximally great entity which is God. For example, advanced extraterrestrials, as in the zoo and planetarium hypotheses may deceive us, but they would not have the maximal greatness of God. The focus in this essay is that the naturally emerging God tends towards the entity of maximal greatness rather than towards a highly advanced entity arising in our own or other universe that we may be deceived into believing is God. The naturally emerging God would have the properties of God and thus truly be God, but would not be a supernatural being.

Maximal greatness may be set by the physical properties and scientific laws of the multiverse and universes involved. Unlimited possibilities may however imply a multitude of gods at various stages of advancement. This could be in line with religions which have many gods. Perhaps one way to generate a single God of maximal greatness would be to imagine a process of merging within this multitude of gods. Another way might involve competition and natural selection between gods. Another might involve collaboration and agreement between gods. Such processes would need to be constrained by whatever physical laws could be operational within the multiverse in relation to the feasibility of interaction between universes and between the gods they contain. One speculation for communication between universes is that this might be via wormholes (Blonde 2016).

Religions could arrive at a conception of this God not only through revelation and reason, but also potentially through scientific investigation given that this God has emerged naturally. But could the hypothesis of a naturally emerging God be tested scientifically? The hypothesis of extraterrestrial civilizations is consistent with current scientific knowledge even if there is no direct evidence that such civilizations exist. The hypothesis of a naturally emerging God may require evidence of both multiple universes and that any advanced entities within these be at the required maximally advanced position on a Kardashev type scale. Multiverse theories do give testable predictions (Page 2006; Tegmark 2003). However, the generation of testable predictions for a natural God emerging out of the multiverse does not look feasible at present. Perhaps the best approach to evidence and testing now would be to focus on the scientific analysis of the Fermi paradox and to try to detect direct evidence of revelation by advanced entities. One explanation of the Fermi paradox, the interdict hypothesis, considers that a "galactic club" of advanced civilizations might have decided to leave life-bearing planets like ours undisturbed (Fogg 1987; Webb 2015). If the revelations by a naturally emerging God were restricted in some similar way, this could frustrate the search for scientific evidence.

\section{A Naturally Emerging God and the Supernatural}

An important part of much religious belief is that God is a supernatural being. Supernatural was originally a religious concept meaning beyond nature, and now refers to something that violates scientific principles and knowledge and includes a wide range of religious phenomena such as gods and immortal souls (Lindeman and Svedholm 2012). If God were a maximally advanced natural entity there would be no requirement for God to be supernatural and beyond natural explanation. God would instead be an inevitable consequence of the natural forces set out in scientific theories. These forces could include those yet unknown to science, and which could provide a scientific explanation for phenomena which now would be classified as supernatural. Given that we cannot predict the scientific knowledge of the future 
(Popper 1961) we cannot know yet what these forces might be. The motives or reasons God would have for making our universe and consequently us perhaps need not differ whether God is supernatural or has emerged naturally.

The existence of a naturally emerging God as an alternative to a supernatural God may be satisfying to some as it brings God within the ambit of science. However, many religious believers may insist on a supernatural God because of the strong faith they have in such a God and they see no need for a naturally emerging God. Instead they may want God to be outside and prior to the multiverse, and then to have created it and all things. This would be in accord with the sovereignty thesis that all causal explanations trace back to God and all that exists is under God's control (Adams 2018). The very existence of time and eternity is debated in both a theological and scientific context (Rogers 1994; Barbour 1999). If eternity has no past or future, then the natural emergence of God from a multiverse might not necessarily entail that the multiverse precedes or is prior to the naturally emerging God.

\section{A Naturally Emerging God and Religious Belief}

At first sight the idea of a naturally emerging God may be more acceptable in deism than theism. In deism emphasis is on the most foundational and rational aspects of religion and can include the notion that after creation God intervened little in the running of our universe (Gomes 2011). Theism envisages God as a designer and creator of unsurpassable power knowledge and goodness who deliberately made our universe with the capability of sustaining life (Holder 2002; Kraay 2010). In theism but not deism God will intervene in the universe through supernatural revelations or miracles, and this perhaps asks much more of a God that emerged naturally. One argument of those atheists who believe that the God of theism does not exist is that it is not rational to believe in the supernatural. This argument is removed or weakened if it is assumed that God emerged naturally by a process which is potentially explicable scientifically. Perhaps other arguments against the existence of God, for example the problem of evil and the argument from inconsistent revelations, do not differ in force between a naturally emerging and supernatural God.

The requirements of God in theism are extremely substantial and demanding. For example, the Wikipedia article on the attributes of God in Christianity lists twenty-eight attributes (see Appendix 2), including omnipotence and omniscience. These attributes and their importance have been the subject of theological and philosophical debate over millennia. Many religions also demand features such as heaven, souls and miracles. In attempting to associate these attributes and features to a naturally emerging God, appeal could again be made to the idea that it is not possible to predict the scientific knowledge of the future. Thus, in the future it might be possible for the descendants of humans to understand scientifically how these attributes and features could be realised by natural processes. For example, perhaps our stream of consciousness with associated memories could be preserved disembodied in a way that we now cannot imagine through current science. Other civilisations elsewhere in our Universe or in other universes may already possess such knowledge. One version of the Kardashev scale involves an extension of the ability to control smaller and smaller entities down to elementary particles, and then to create organized complexity from them (Barrow 1998). Exploitation of this knowledge could perhaps render naturally what are called miracles, through transformation or creation of matter. Some of the attributes (Appendix 2) seem compatible with a naturally emerging God without the need to appeal to as yet unknown scientific forces.

One motive for this essay is to ask whether the belief and faith in a God that has emerged naturally and inevitably in an eternal existence of multiple universes could be consistent with or acceptable to major religions or religious perspectives or practice? Could this belief be tolerated? Is it strictly necessary to believe in a supernatural God? Given the great diversity of religions, could belief in a naturally emerging God be subsumed into the totality of religious belief? Perennialism emphasizes the underlying unity that the similarities between religions disclose, and that the one God in revelation is impartial, evidenced by long-term survival of the great religions (Smith 1987). From this perspective, to rationalize belief in a naturally emerging God, emphasis could be attached to the similarities between this belief and the beliefs of major religions rather than on the differences, such as belief or not in the supernatural. 


\title{
Appendix 1
}

\section{Examples of science fiction stories that include superintelligences or godlike entities}

\author{
"The Last Question" by Isaac Asimov
}

Humanity produces a godlike descendent that is spread throughout the universe, in parallel with a succession of computers called Multivac which eventually fuse with humanity. As the universe dies out AC the ultimate Multivac pronounces "LET THERE BE LIGHT!" And there was light.

\section{"Childhood's End" by Arthur C. Clarke}

Aliens serving a vast cosmic intelligence called the Overmind arrive in spacecraft and begin to supervise and sometimes to intervene in human affairs. The minds of human children merge into a single consciousness in preparation for joining the Overmind and the disappearance of the material planet Earth.

\section{"Mr g: A Novel About the Creation" by Alan Lightman}

God (Mr g) is disturbed by his aunt and uncle Penelope and Deva with whom he lives and decides by trial and error to create a universe with intelligent humanity. Mr $\mathrm{g}$ is omnipotent but not omniscient and is challenged by a rival to exempt humans from rational laws.

\section{"Star Maker" by Olaf Stapledon}

The mind of the human narrator merges with those of inhabitants of other planets to form a cosmic mind which meets the Star Maker a creator of Universes including the narrator's universe, and other universes like hell and heaven.

\section{Appendix 2}

\section{"Attributes of God in Christianity", taken from Wikipedia (April 2020)}

Aseity (7); Eternity (8); Goodness (9,10); Graciousness (11); Holiness (12); Immanence (13); Immutability (14-16); Impassibility (17-21); Impeccability (22,23); Incomprehensibility (24); Incorporeality (25); Infinity $(26,27)$; Jealousy (28); Love (29,30); Mission (31,32); Mystery (33-36); Omnipotence (37); Omnipresence (38); Omniscience (39); Oneness (40); Providence (41,42); Righteousness (43); Simplicity (44); Sovereignty (45-47); Transcendence (48); Trinity (49,50); Veracity (51); Wrath (52).

Numbers above are exactly those in the Wikipedia reference list below. beginning at number 7 .

(7) D. A. Carson, The Gagging of God (Grand Rapids: Zondervan), 1996. (8) Wayne Grudem, Systematic Theology, 168. (9) Wayne Grudem, Systematic Theology, 197. (10) Louis Berkhof, Systematic Theology, 70-72. (11) Middot, Shelosh-'Esreh". Jewish Encyclopedia. (12) R. C. Sproul, The Holiness of God (Scripture Press Foundation, 1986), 38. (13) Jump up to:a b Wayne Grudem, Systematic Theology, 267. (14) Herman Bavinck, The Doctrine of God, 146. (15) Millard Erickson, Christian Theology, 279. (16) D. A. Carson, The Difficult Doctrine of the Love of God, 63. (17) James F. Keating and Thomas Joseph White (eds.), Divine Impassibility and the Mystery of Human Suffering. Grand Rapids: Eerdmans, 2009. (18) Rowland S. Ward, The Westminster Confession for the Church Today, 27. (19) Robert L. Reymond, A New Systematic Theology of the Christian Faith (2nd ed., Nashville: Thomas Nelson, 1998), 179. (20) D. A. Carson, The Difficult Doctrine of the Love of God, 55. (21) D. A. Carson, The Difficult Doctrine of the Love of God, 68. (22) Edward R. Wierenga, The Nature of God: An Inquiry Into Divine Attributes (Cornell University Press, 1989), p. 203. (23) Robert A. Morey, Exploring The Attributes Of God, p. 65. (24) Louis Berkhof, Systematic Theology (London: Banner of Truth, 1949), 43. (25) Robert L. Reymond, A New Systematic Theology of the Christian Faith (2nd ed., Nashville: 
Thomas Nelson, 1998), 167. (26) Brendan Kneale, "God and Mathematical Infinity" Perspectives on Science and Christian Faith 50 (1998). (27) Yujin Nagasawa, The Existence of God (Taylor \& Francis, 2011), p. 111. (28) J. I. Packer, Knowing God, p. 154. (29) Carson, Donald Arthur (2010) [2000]. The Difficult Doctrine of the Love of God (reprint, revised ed.). London: Inter-Varsity Press. p. 10. ISBN 1-84474427-2. ISBN 978-1-844-74427-5. (30) Kevin J. Bidwell, "Losing the Dance: is the 'divine dance' a good explanation of the Trinity?" in Iain D. Campbell and William M. Schweitzer (eds), Engaging with Keller: Thinking through the theology of an influential evangelical (Evangelical Press, 2013), p. 106. (31) David J. Bosch, Transforming Mission (Maryknoll: Orbis Books, 1991), 390. (32) Christopher J. H. Wright, The Mission of God: Unlocking the Bible's Grand Narrative, p. 36. (33) William Stacy Johnson, The Mystery of God: Karl Barth and the Postmodern Foundations of Theology (Westminster John Knox, 1997), 5. (34) Karl Rahner, "Reflections on Methodology in Theology" in Theological Investigations, (Darton, Longman \& Todd Ltd., 1991), vol. 11, 100,102. (35) N. A. Berdyaev (Berdiaev), "A Consideration Concerning Theodicy" (1927 - \#321), translator Fr. S. Janos, Berdyaev.com, accessed November 12, 2009. (36) Ian T. Ramsey, Models and Mystery, 61. (37) C. S. Lewis, The Problem of Pain (Fontana, 1966), 16. (38) Louis Berkhof, Systematic Theology (London: Banner of Truth, 1949 ), 61. (39) Louis Berkhof, Systematic Theology (London: Banner of Truth, 1949), 68. (40) The IVP Women's Bible Commentary, p. 96. (41) Freddoso, Alfred J. "Divine Attributes: Providence". University of Notre Dame. Retrieved 17 February 2013. (42) Providence in The Concise Oxford Dictionary of World Religions. (43) Wright, N. T. (1997). What St Paul Really Said. p. 102. ISBN 9780745937977. (44) Wayne Grudem, Systematic Theology, 177-178. (45) A. W. Pink, The Sovereignty Of God Archived March 12, 2013, at the Wayback Machine. (46) Morris, Robert. "Why Keep Praying?". Faith Gateway. Retrieved 21 January2019. (47) "Prayer and Its Place in God's Sovereign Plan". Focus on the Family. Retrieved 22 January 2019. (48) J. Gresham Machen, God Transcendent. Banner of Truth publishers, 1998. ISBN 0-85151-355-7. (49) Alister McGrath, Understanding the Trinity, p. 120. (50) John Painter and Daniel J. Harrington, 1, 2, and 3 John. (51) Greg Bahnsen, "The Inerrancy of the Autographa". (52) Wayne Grudem, Systematic Theology, 205.

\section{References}

D. Adams. God and Dispositional Essentialism: An Account of the Laws of Nature. Pacific Philosophical Quarterly, 99:293-316, 2018.

J.A. Ball. Zoo Hypothesis. Icarus, 19:347-349, 1973.

J. Barbour. The End of Time. Oxford University Press, 1999.

J. Barrow. Impossibility: Limits of Science and the Science of Limits. Oxford University Press, 1998.

S. Baxter. The Planetarium Hypothesis: a Resolution of the Fermi paradox. Journal of the British Interplanetary Society, 54:210-216, 2000.

W. Blonde. Can an eternal life start from the minimal fine-tuning for intelligence? Philosophy and Cosmology, 17:26-38, 2016.

M.H. Chan. Would God Create our Universe through Multiverse? Theology and Science, 13:395-408, 2015.

M.M. Cirkovic. Kardashev's Classification at 50+: A Fine Vehicle with Room for Improvement. Serbian Astronomical Journal, 191:1-15, 2015.

M.M. Ćirković. The great silence: science and philosophy of Fermi's paradox. Oxford University Press, 2018.

A.C. Clarke. Profiles of the Future: An Inquiry into the Limits of the Possible. Popular Library, 1973.

C. Clarkson, B. Bassett, and T.H. Lu. A general test of the Copernican Principle. Physical Review Letters, 101:011301, 2008.

D.P.G. da Costa. Reviewing the Concept of Technological Singularities: How Can It Explain Human Evolution? Nanoethics, 13:119-130, 2019. 
F. Drake and D. Sobel. Is Anyone Out There? The Scientific Search for Extraterrestrial Intelligence. Delta, 1992.

M.J. Fogg. Temporal Aspects of the Interaction Among the 1st Galactic Civilizations - The Interdict Hypothesis. Icarus, 69:370-384, 1987.

D.H. Forgan. A numerical testbed for hypotheses of extraterrestrial life and intelligence. International Journal of Astrobiology, 8:121-131, 2009.

A. Frank and W.T. Sullivan. A New Empirical Constraint on the Prevalence of Technological Species in the Universe. Astrobiology, 16:359-362, 2016.

Z. Galantai. Long Futures and Type IV Civilizations. pdf on website of author, September 2003.

A.W. Gomes. Deism. The Encyclopedia of Christian Civilization, 2011.

J. Gribbin. In Search of the Multiverse: Parallel Worlds, Hidden Dimensions, and the Ultimate Quest for the Frontiers of Reality. Wiley, 2010.

D. Grumett. Teilhard de Chardin's evolutionary natural theology. Zygon, 42:519-534, 2007.

A.H. Guth. The inflationary universe: the quest for a new theory of cosmic origins. Basic Books, 1997.

E.R. Harrison. The natural selection of universes containing intelligent life. Quarterly Journal of the Royal Astronomical Society, 36:193-203, 1995.

R.D. Holder. Fine-tuning, multiple universes and theism. Nous, 36:295-312, 2002.

N.Y. Ignatova. The Concept of a Multiverse (Multiple Worlds) in Skeptical Theism. Tomsk State University Journal, (439):95-102, 2019.

R.H. Kane. Nature, Plenitude and Sufficient Reason. American Philosophical Quarterly, 13:23-31, 1976.

N.S. Kardashev. Transmission of Information by Extraterrestrial Civilizations. Soviet Astronomy, 8: 217-221, 1964.

K.J. Kraay. Theism, possible worlds, and the multiverse. Philosophical Studies, 147:355-368, 2010.

K.J. Kraay. Megill's multiverse meta-argument. International Journal for Philosophy of Religion, 73: 235-241, 2013.

H. Kragh. Plenitude Philosophy and Chemical Elements. Hyle, 25:1-20, 2019.

R. Kurzweil. The Singularity is Near. Penguin, 2005.

S.R. Levin, T.W. Scott, H.S. Cooper, and S.A. West. Darwin's aliens. International Journal of Astrobiology, 18:1-9, 2019

M. Lindeman and A. M. Svedholm. What's in a Term? Paranormal, Superstitious, Magical and Supernatural Beliefs by Any Other Name Would Mean the Same. Review of General Psychology, 16: $241-255,2012$.

A.O. Lovejoy. The Great Chain of Being: A Study of the History of an Idea [1936]. Harvard University Press, 1976.

J. Megill. Evil and the many universes response. International Journal for Philosophy of Religion, 70: 127-138, 2011.

G. Oppy. Ontological Arguments (edited by Oppy, G.). Routledge, 2018.

D.N. Page. Predictions and tests of multiverse theories. 2006. arXiv:hep-th/0610101v1.

D.N. Page. Does God so love the Multiverse. 2008. arXiv:0801.0246.

K.R. Popper. The Poverty of Historicism. Routledge, 1961.

R.R. Richey. God as the Answer to Fermi's Paradox. pdf in Sandstone Magazine, April 2019.

K.A. Rogers. Eternity has no Duration + Medieval Philosophy. Religious Studies, 30:1-16, 1994. 
K.A. Rogers. Classical theism and the multiverse. International Journal for Philosophy of Religion, 2020.

M. Rowan-Robinson. Cosmology. Oxford University Press, 1996.

A. Sandberg, E. Drexler, and T. Ord. Dissolving the Fermi Paradox. 2018. arXiv:1806.02404v1.

M. Shermer. Shermer's last law - Any sufficiently advanced extraterrestrial intelligence is indistinguishable from god. Scientific American, 286:33-33, 2002.

H. Smith. Is there a Perennial Philosophy. Journal of the American Academy of Religion, 55:553-566, 1987.

Lee Smolin. The Life of the Cosmos. Oxford University Press, 1997.

Lee Smolin. Cosmological natural selection as the explanation for the complexity of the universe. Physica A: Statistical Mechanics and its Applications, 340:705 -713, 2004.

R.J. Spitzer. A Contemporary Metaphysical Proof for the Existence of God. International Philosophical Quarterly, 59:427-466, 2019.

M. Tegmark. The Coming Technological Singularity: How to Survive in the Post-Human Era. In J.D. Barrow, P.C.W. Davies, and C.L. Harper, editors, Science and Ultimate Reality: From Quantum to Cosmos, honoring John Wheeler's 90th birthday. Cambridge University Press, 2003.

R. Vaas. Problems of cosmological darwinian selection and the origin of habitable universes. In P.A. (Shaver, L. DiLella, and A.) Giminez, editors, Astronomy, cosmology and fundamental physics, pages 485-486. Springer, 2003.

M. Vardanyan, R. Trotta, and J. Silk. Applications of Bayesian model averaging to the curvature and size of the Universe. Monthly Notices of the Royal Astronomical Society, 413:L91-L95, 2011.

C. Vidal. A multidimensional impact model for the discovery of extraterrestrial life. In S.J. Dick, editor, The Impact of Discovering Life Beyond Earth. Cambridge University Press, 2015.

V. Vinge. The Coming Technological Singularity: How to Survive in the Post-Human Era. In G.A. Landis, editor, Vision-21: Interdisciplinary Science and Engineering in the Era of Cyberspace. NASA Publication CP-10129, 1993.

S. Webb. If the Universe is Teeming with Aliens... Where is Everybody? Seventy-Five Solutions to the Fermi Paradox and the Problem of Extraterrestrial Life. Springer, 2015.

T.L. Wilson. The search for extraterrestrial intelligence. Nature, 409:1110-1114, 2001.

R. Zubrin. The great silence: science and philosophy of Fermi's paradox. Oxford University Press, 1999. 